\title{
IRREGULAR FLOWERING REGIMES IN ORCHIDS
}

\author{
Pavel KindlmanN \\ Faculty of Biological Sciences, University of South Bohemia, Branisovska 31 \\ 37005 Ceske Budejovice, Czech Republic, and \\ CNRS, UMR ECOBIO, Université de Rennes 1, Campus de Beaulieu, 35042 Rennes Cedex, France
}

Many orchids are characterised by their so-called irregular flowering regime, which is an irregular sequence of flowering, dormant and sterile stages during the life of one individual (Curtis \& Green 1953, Tamm 1956, 1972, 1991, Wells 1967, 1981, 1994, Hutchings 1987, Firmage \& Cole 1988, Inghe \& Tamm 1988, Wells \& Cox 1991, Willems \& Bik 1991, Whigham \& O’Neill 1991, Jones 1998, Hutchings et al. 1998, Willems \& Melser 1998, Kindlmann 1999, Kindlmann \& Balounová 1999a, 2001, Kindlmann et al. 2002). Here I would like to review alternative hypotheses that aim to explain this phenomenon.

Stochasticity. The transition probabilities from one stage in a particular year to another stage the next year (e.g., flowering one year - dormant the next year etc.) lead to matrix models (Gregg 1991, Waite \& Hutchings 1991). Being stochastic, they - by definition - lead to a seemingly "chaotic" behaviour. Can there, however, be predicted anything more than a probability of flowering, being sterile or dormant, if there are other predictable patterns in orchid behaviour?

Possible artefacts of data collection. A plant that initiated an inflorescence might subsequently, but before the observation has been done, have been grazed completely and thus considered as being absent. As shown in Kindlmann \& Balounová (1999a), however, there is almost no difference between the results for one and multiple observations per year. Thus, for observations of transitions between individual life stages one observation per year would suffice.

Inghe's hypothesis. Inghe (1990) tried to explain irregular flowering patterns by means of computer simulations of difference equations. Assuming a deterministic (exponential or logistic) growth of the vegetative dry weight and a deterministic relationship between vegetative and reproductive dry weight, he concluded that the irregular flowering patterns within one plant might be partly explained by the chaotic behaviour of the corresponding difference equations. Kindlmann (1999) has shown that the irregular flowering pattern in Epipactis albensis cannot be explained by Inghe's (1990) hypothesis. Shoot height in sterile plants is always small, but sterility or dormancy cannot be predicted from shoot height and number of flowers in the preceding year.

Stochasticity of the environment. The decision on whether the plant will flower, be sterile or remain dormant, is made early in the season or late in the preceding season (Leeson et al. 1991). Reserve size is one factor in this decision and microhabitat environmental conditions at this time are probably the other. The latter assumption cannot be applied to global environmental conditions, as it would lead to the same strategy in different plants with the same history and this is not supported by empirical data. There is no reason for not believing that evolution shaped the plant strategies in the direction of optimisation of their energy budget. Therefore, optimum energy-partitioning models (e.g., Kindlmann \& Balounová 1999b), should be able to explain the irregular flowering pattern.

It is well known and strongly supported by Tamm (1972) and others that there are certain "orchid years" in which most of them flower, while in other years, almost no plants flower. Wells et al. (1998) have shown that weather is a major factor causing whole populations not to flower.

Grazing. Whigham (1990) has reported a negative effect of defoliation on the belowground corms. Kindlmann \& Balounová (1999a), however, claim 
that in most cases grazing does not seem to account for the "not explained" cases in populations of Dactylorhiza majalis.

This discrepancy may be explained as follows: Defoliation, which imitates insect feeding, leaf diseases etc., lowers assimilation and therefore the size of overwintering storage organs (next year tuber), which may then become of subcritical size and cause sterility the next year. Grazing by large mammals like deer, however, is not selective and in most cases both leaves and inflorescence are grazed. Thus, although in this case assimilation is lowered, too, the plant "saves" energy by not spending it on costly reproduction and in many cases the resulting storage size is not affected. It would be nice to test this hypothesis experimentally.

The effect of grazing on orchid populations also probably depends on its timing and intensity: Wells (pers. comm.) reports that grazing by large mammals (e.g., sheep, cattle) can have a devastating effect on orchid populations and can have a major effect on flowering. Grazing by rabbits both destroys the habitat and also results in severe defoliation of certain species (Wells, pers. comm.). On the other hand, a good sheep grazing management can maintain thriving orchid populations for years and cause them to significantly increase in numbers, as is the case of the populations in South Limburg (Willems, 1989, Willems and Lahtinen 1997). Therefore, the effect of grazing is ambiguous and would deserve further studies.

Cost of reproduction. The negative effect of a large investment into reproduction that leads to sterility or dormancy the next year has been reported by Whigham \& O'Neill (1991). However, there might be a difference with respect to this between deceptive orchid species (species which do not produce any nectar, therefore "deceit" the pollinators and rely on naive ones, which pollinate them by mistake) and rewarding ones (nectar producing, offering reward to pollinators) for the following reason:

The reproductive success (RS) of rewarding species is mostly close to $100 \%$, thus - more importantly variation in RS is low. Thus evolution might have adjusted the dependence of the number of flowers produced on storage size. As a consequence, storage size is not significantly affected by the small variation in RS and once attained the above-critical size for flowering, this size will be kept for years.

In deceptive species, on the other hand, variation in RS is extreme (Jersáková \& Kindlmann 1998) and therefore evolution had to adjust the dependence of the number of flowers produced on storage size with respect to the expectation of some average RS. Thus the size of overwintering storage organs strongly depends on RS in the preceding season, which because of deceptivity - varies dramatically. In plants which happened to have an above-average RS in some season it may happen that storage which was of above-critical size the previous year becomes subcritical the next year.

Habitat deterioration. Kindlmann \& Balounová (1999a) suggested that the observed irregular flowering regimes should be typical for sites with declining populations - either because of unsuitable habitat, deteriorating management or for unsuitable weather conditions in a particular year.

If correct, the hypothesis that irregular flowering regimes are characteristic for sites with temporarily or steadily declining populations and not usually present in prosperous ones could account for the controversy between predictions of theoretical models and empirical observations, at least in some species. If both climatic and habitat conditions are good, irregular flowering should not be the case. If either of these conditions gets worse, transitions from flowering to sterility or absence may become more frequent and lead eventually to extinction of the population.

Conclusions. The irregular flowering patterns in orchids are neither an artefact of the way the data were collected, nor a result of chaotic behaviour of mathematical equations. The literature reviewed here shows that they are caused by a complex of biotic and abiotic factors, which can act both ways and it depends on the site and species, which one is the most important. These factors include: 1) weather; 2) grazing by mammals, by insects and underground grazing of storage organs; 3) leaf diseases; 4) cost of reproduction in species, in which reproductive success varies substantially; 5) habitat management and 6) habitat deterioration. 


\section{ACKNOWLEDGEMENTS}

This research was supported by the grants No. MSM 123100004 of the Czech Ministry of Education and K6005114 of the Czech Academy of Sciences.

\section{Literature Cited}

Curtis, J.T. and H. Green. 1953. Population changes in some native orchids of southern Wisconsin, especially in the University of Wisconsin Arboretum. Orchid Journal 2: $152-155$.

Firmage, D.H. and F.R. Cole. 1988. Reproductive success and inflorescence size of Calopogon tuberosus (Orchidaceae) Am. J. Bot. 75: 1371-1377.

Gregg, K.B. 1991. Variation in behaviour of four populations of the orchid Cleistes divaricata, an assessment using transition matrix models. In: Wells, T.C.E. and J.H. Willems (eds.), Population ecology of terrestrial orchids. SPB Acad. Publ. bv, The Hague, pp. 139-159.

Hutchings, M.J. 1987. The population biology of the early spider orchid, Ophrys sphegodes Mill. I. A Demographic study from 1975 to 1984. J. Ecol. 75: 711-727.

Hutchings, M.J., A. Mendoza and W. Havers. (1998) Demographic properties of an outlier population of Orchis militaris L. (Orchidaceae) in England. Bot. J. Linn. Soc. 126: 95-107.

Inghe, O. 1990. Computer simulations of flowering rhythms in perennials - is there a new area to explore in the quests for chaos? J. Theor. Biol. 147: 449-469.

Inghe, O. and C.O. Tamm. 1988. Survival and flowering of perennial herbs. V. Patterns of flowering. Oikos 51: 203-219.

Jersáková, J. and P. Kindlmann. 1998. Patterns of pollinator-generated fruit set in Orchis morio (Orchidaceae). Folia Geobot. 33: 377-390

Jones, P.S. 1998. Aspects of the population biology of Liparis loeselii (L.) Rich. var. ovata Ridd.ex Godfery (Orchidaceae) in the dune slacks of South Wales, UK. Bot. J. Linn. Soc. 126: 123-139.

Kindlmann, P. 1999. Are orchid life histories really irregular? The case of Epipactis albensis. Oikos 85: 265-270.

Kindlmann P. and Z. Balounová. 1999a. Flowering regimes of terrestrial orchids: chaos or regularity? J. Veg. Sci. 10: 269-273.

Kindlmann P. and Z. Balounová. 1999b. Energy partitioning in terrestrial orchids - a model for assessing their performance. Ecol. Modelling 119: 167-176.

Kindlmann, P. and Z. Balounová. 2001. Irregular flowering patterns in terrestrial orchids: theories vs. empirical data. Web Ecol. 2: 75-82.

Kindlmann P., J.H. Willems and D.F. Whigham (eds.). 2002. Trends and fluctuations and underlying mechanisms in terrestrial orchid populations. Backhuys, The Netherlands.

Leeson, E., Haynes, C., Wells, T.C.E. 1991. Studies of the phenology and dry matter allocation of Dactylorhiza fuchsii. In: Wells, T.C.E. and J.H. Willems (eds.), Population ecology of terrestrial orchids. SPB Acad. Publ. bv, The Hague, pp. 125-138.

Tamm, C.O. 1956. Further observations on the survival and flowering of some perennial herbs. Oikos 7: 274292.

Tamm, C.O. 1972. Survival and flowering of some perennial herbs. II. The behaviour of some orchids on permanent plots. Oikos 23: 23-28.

Tamm, C.O. 1991. Behaviour of some orchid populations in a changing environment: Observations on permanent plots, 1943-1990. In: Wells, T.C.E. and J.H. Willems (eds.), Population Ecology of Terrestrial Orchids. SBP Academic Publishing, The Hague, pp. 1-13.

Waite, S. and M.J. Hutchings. 1991. The effects of different management regimes on the population dynamics of Ophrys sphegodes: analysis and description using matrix models. In: Wells, T.C.E. and J.H. Willems (eds.), Population ecology of terrestrial orchids. SPB Acad. Publ. bv, The Hague, pp. 161-175.

Wells, T.C.E. 1967. Changes in a population of Spiranthes spiralis (L.) Chevall. at Knocking Hoe National Nature Reserve, Bedfordshire, 1962-65. J. Ecol. 55: 83-99.

Wells, T.C.E. 1981. Population ecology of terrestrial orchids. In: Synge, H. (ed.), The biological aspects of rare plant conservation, Huntingdon, England, pp. 281295.

Wells, T.C. E. 1994. Population ecology of British terrestrial orchids. In: Pridgeon, A. M. (ed.) Proceedings of the 14th World Orchid Conference, HMSO, Edinburgh, UK, pp. 170-175.

Wells, T.C.E., Cox, R. 1991. Demographic and biological studies on Ophrys apifera: some results from a 10 year study. In: Wells, T.C.E. and J.H. Willems (eds.), Population ecology of terrestrial orchids. SPB Acad. Publ. bv, The Hague, pp. 47-61.

Wells, T.C.E., P. Rothery, R. Cox and S. Bamford. 1998. Flowering dynamics of Orchis morio L. and Herminium monorchis (L.) R.Br. at two sites in eastern England. Bot. J. Linn. Soc. 126: 39-48.

Whigham, D.F. 1990. The effect of experimental defoliation on the growth and reproduction of a woodland orchid, Tipularia discolor. Can. J. Bot. 68: 1812-1816.

Whigham, D.F., O'Neill, J. 1991. The dynamics of flowering and fruit production in two eastern North American terrestrial orchids, Tipularia discolor and Liparis lilifo lia. In: Wells, T.C.E. and J.H. Willems (eds.), Population ecology of terrestrial orchids. SPB Acad. Publ. bv, The Hague, pp. 89-101.

Willems, J.H. 1989. Population dynamics of Spiranthes spiralis in South-Limburg, The Netherlands. Mém. Soc. Roy. Bot. Belg. 11: 115-121.

Willems, J.H. and L. Bik. 1991. Long-term dynamics in a population of Orchis simia in the Netherlands. In: Wells, T.C.E. and J.H. Willems (eds.), Population Ecology of 
Terrestrial Orchids, pp. 33-45 SBP Academic Publishing, The Hague, The Netherlands.

Willems J.H. and M.L. Lahtinen. 1997. Impact of pollination and resource limitation on seed production in a border population of Spiranthes spiralis (Orchidaceae).
Acta Bot. Neerl. 46: 365-375.

Willems, J.H., Melser, C. 1998. Population dynamics and life-history of Coeloglossum viride (L.) Hartm.: an endangered orchid species in The Netherlands. Bot. J. Linn. Soc. 126: 83-93.

Prof. Pavel Kindlmann works on modeling of population dynamics and of pollination strategies of terrestrial orchids. 